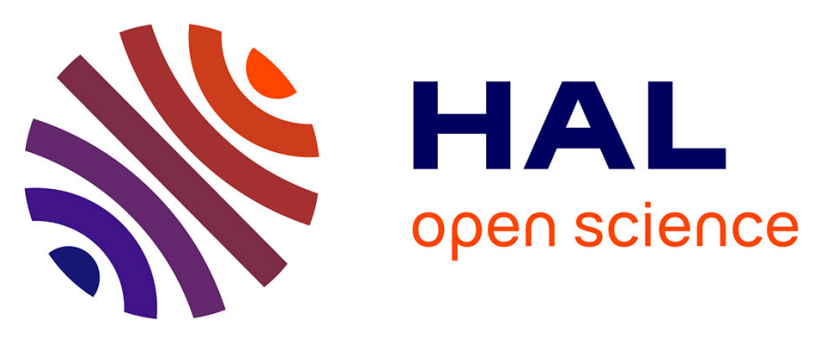

\title{
Eco-process Engineering System for Collaborative Product Process System Optimisation
}

\author{
Juhani Heilala, Reino Ruusu, Jari Montonen, Saija Vatanen, Carlos Kavka,
} Fabio Asnicar, Sebastian Scholze, Alberto Armiojo, Mario Insunza

\section{To cite this version:}

Juhani Heilala, Reino Ruusu, Jari Montonen, Saija Vatanen, Carlos Kavka, et al.. Eco-process Engineering System for Collaborative Product Process System Optimisation. IFIP International Conference on Advances in Production Management Systems (APMS), Sep 2014, Ajaccio, France. pp.634641, 10.1007/978-3-662-44736-9_77 . hal-01387944

\section{HAL Id: hal-01387944 \\ https://hal.inria.fr/hal-01387944}

Submitted on 26 Oct 2016

HAL is a multi-disciplinary open access archive for the deposit and dissemination of scientific research documents, whether they are published or not. The documents may come from teaching and research institutions in France or abroad, or from public or private research centers.
L'archive ouverte pluridisciplinaire HAL, est destinée au dépôt et à la diffusion de documents scientifiques de niveau recherche, publiés ou non, émanant des établissements d'enseignement et de recherche français ou étrangers, des laboratoires publics ou privés. 


\title{
Eco-Process Engineering System for Collaborative Product Process System Optimisation
}

\author{
Juhani Heilala $^{1}$, Reino Ruusu ${ }^{1}$, Jari Montonen ${ }^{1}$, Saija Vatanen ${ }^{1}$ Carlos Kavka ${ }^{2}$, Fabio \\ Asnicar $^{2}$, Sebastian Scholze $^{3}$, Alberto Armiojo ${ }^{4}$, Mario Insunza ${ }^{5}$ \\ ${ }^{1}$ VTT Technical Research Centre of Finland, PO Box 1000, FI-02044 VTT, Finland \\ Primary Contact: Juhani Heilala <juhani.heilala@vtt.fi> \\ ${ }^{2}$ ESTECO, AREA Science Park, Padriciano 99, 34149 Trieste, Italy \\ ${ }^{3}$ ATB, Institut für angewandte Systemtechnik Bremen GmbH, Wiener Straße 1, 28359 Bremen, \\ Germany \\ ${ }^{4}$ TECNALIA, Parque Científico y Tecnológico de Bizkaia - C/ Geldo. Edificio 700. E-48160 \\ Derio, Spain \\ ${ }^{5}$ SISTEPLANT, S.L. - Parque Tecnológico de Bizkaia, 607 building, 48160 Derio, Spain.
}

\begin{abstract}
Eco-Process engineering system (EPES) means systematic collaborative eco-efficiency and eco-innovation aspects in product service system (PSS) development and management, and covers all life-cycle phases. It is an ICT tool and related application methodology. The development focus on PSS from functional and cost performance is currently enhanced with sustainability aspects. The goal is to create more value with less environmental impact. In the virtual factories, extended enterprises, the collaboration between different stakeholders, engineers, managers, users of the PSS is a must and all actors in the value chain need a common goal. EPES system provides a collaborative space, covering common data and functionalities for knowledge management, multi-objective decision making, simulation and optimisation. Coordinated evolution (co-evolution) of products, processes and services creates competitive advantage. This paper shows a prototype of EPES system. The software building blocks of EPES system are illustrated as well methodology steps in setting up system and using it.
\end{abstract}

Keywords: product service system, life-cycle optimisation, collaborative space

\section{$1 \quad$ Introduction}

The focus of product, process or service design is currently rapidly widening to include additional goals related to sustainability, especially in the field of energy and energy-intensive industry [1]. In addition to economic, functional performance, product, process and service quality and marketability issues, new social and environmental aspects are increasingly taken into account.

Examples of the drivers of this development are: Cost savings, resource efficiency, regulations set by society, directives, standards, also customer requirements and communication, business reputation and so on. The eco-constraints, e.g. resource 
efficiency, energy consumption, emission, hazardous waste, etc., need to become a part of the wider assessment of the overall Product, Process and Service (PPS) feasibility analysis, engineering development and management.

The nature of sustainability as a holistic viewpoint presents a need for complex multi-objective decision-making, in which compromises need to be made between mutually exclusive criteria. Additionally all the stages of the life cycle of a product service system need to be taken into account in the development stage. This greatly increases the quantity of good-quality data that needs to be presented to decisionmakers. This data is not only hard to collect but subject to continuous change, due to technological development [2].

In order to address complex multi-objective decision-making in a distributed world of the extended enterprise, flexible tools that provide support for knowledge management, communication, co-operation and business process management are needed [3]. Service-oriented ICT tools are one enabler for efficient networking. A need for efficient Business Process Management (BPM) arises to orchestrate the activities carried by the various actors that do not necessarily fit within a single productoriented organizational structure.

Selection of the best design among a set of alternatives is a very important task in the development stage of a PPS. Modelling and simulation techniques are necessary in order to account for future effects of design decisions.

In most engineering environments, designers need to be encouraged to integrate environmental aspects by increasing the availability of suitable tools and knowledge. Integration of sustainability aspects to various simulation models is still rare [4]. One example of development is shown in [5]. In short, the main requirements should include: A simple and easy to use method; Availability of appropriate data; Clear and easily communicable results; and Traceable conclusions.

Above all, any tools or information deployed as part of Design for Environment (DfE) should be fully integrated in an existing design process, procedures and manuals. Environment aspects should become a new key parameter to consider in decisionmaking, alongside technical performance, safety and cost [6].

In the EPES project, a software service platform is created for bridging the gap between design-oriented tools, such as CAD and CAE, operations and service planning tools and tools for managing the business decision-making. Partially this is the traditional domain of PLM systems, most of which are, however, quite costly and inflexible.

The idea of EPES is to provide the users with a product-process-service (PPS) development-oriented "collaborative space" that can be organized by its users without customization by a software vendor, but allowing a level of integration of tools and databases that is not available on general purpose collaboration platforms.

\section{New way of working}

The EPES project is developing a comprehensive software platform that allows engineering issues to be addressed from the multiple points-of-view of sustainability. The 
EPES system is an integrated Enterprise Content Management (ECM) and Business Process Management (BPM) platform that provides general advantages as an engineering and/or decision-making platform [7, 8, 9, 10]. Its focus is on efficient interdisciplinary co-operation, communication, data collection and management. It also serves as a tool for communication between the engineering community and the strategic decision-makers, allowing them to make informed decisions at the earliest stages of the PPS development and management.

The platform provides functionalities for:

- Knowledge Management, in the form of an enterprise content management system, which is augmented with a semantic context database for providing additional meta-data

- Business Process Management, in the form of a BPM platform on which complex processes can be modelled using BPMN 2.0.

- IT service automation that provides additional support for meta-data collection and processing and automating the execution of complex computational processes for producing the key performance indicators that are needed for decision-making.

- Multi-objective simulation and optimization, in the form of an integrated state-of-the art solution.

- Business Intelligence, in the form of a data integration and analytics platform.

In order to provide maximum accessibility in a distributed environment, the platform is built to be operated in a strictly browser-based user interface.

In the EPES project business cases, the core eco-efficiency objectives are: Increase product or service value, optimizing the use of resources, and reduce environmental impact. The business cases are diverse, and include electric grid design and operation, wind turbine maintenance operations and aircraft wing design from the point of view of manufacturability (see chapter 4 ).

The overall EPES reference architecture schema is illustrated in Figure 1

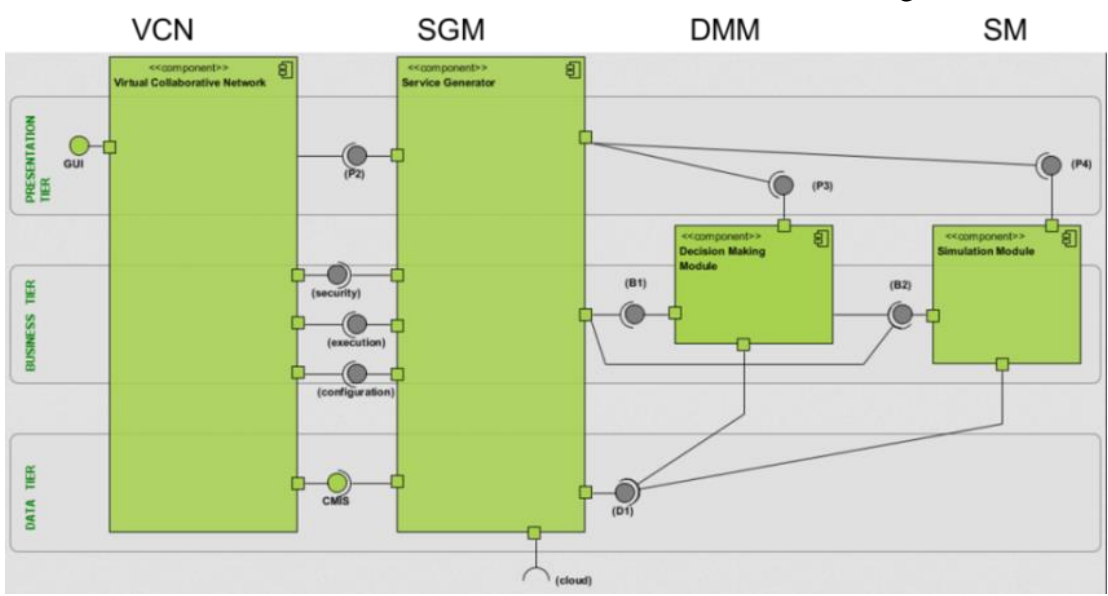

Fig. 1. EPES Architecture Schema. 
EPES is separated into a three-layered structure that complies in every layer to a service oriented approach. Three layers are: Data tier, Business Tier and Presentation tier (see Fig 1.).

Based on the service-oriented development approach, that represents several different processes as services that are fully interoperable and allow further re-use for specific process reoccurrences. All layers of the EPES system concept are seen as a part of an overall service structure so that every component could interact with each other, but is additionally focused around specific transition services.

The EPES system is built upon the following core services, VCN, SGM, DMM and SM (see Fig 1.).

Virtual Collaborative Network (VCN): The VCN main functionality is to provide a main point of access for non-expert end-users through user interfaces, including capabilities for supporting the aggregated Graphical User Interfaces (GUI) provided by the Service Generator. It provides the technical infrastructure for the distribution of users into groups; content management and sharing mechanisms; workflow engine for contents production, consumption and transformation. In addition, the VCN provides a Knowledge Base, containing actual data, historical data, identified constraints and objectives from collaborative networks, KPIs and Life-Cycle Inventory data.

Service Generator (SG): The Service Generator's main functionality is creating, updating, and deploying configurations for application-specific services. It interacts with the Simulation Module and the Decision Making Module to compute parameters for updated configurations. The SG can also store / retrieve configurations in/from the Virtual Collaborative Network. Finally, the SG allows identification of contextual information about EPES solution operators as well as connected legacy systems.

Simulation Module (SM): The simulation module of the presented platform provides a capability for running numerical analyses related to the life-cycle assessment process. It provides simulation services through an abstract service interface that allows higher-level components of the platform to use simulation as an interchangeable service, according to the principles of the Service Oriented Architecture (SOA) design paradigm. It allows the other modules to present configuration options and numerical parameters of simulation modules without any prior knowledge of the internal structure of the model.

Decision Making Module (DMM): DMM is an interactive system intended to help decision-makers to use data and models to identify and solve problems and to make decisions. On the one hand, there will be some traditional indicators for measuring the overall PSS performance, but on the other hand, there will be new KPIs established and defined in the DMM. These KPIs will be traced to the measured constraints, and the DMM will show, where the constraints are, and how to measure the performance of the organization, in order to take the best decision in a range of values proposed by the SM taking into account the localized constraint. The KPIs taken into consideration will mostly reflect eco constraints. Inputs from the SM will support the decision process, by simulating the potential evolution of relevant KPIs and allowing thus taking informed decisions. 


\section{EPES prototype}

The existing EPES prototype platform makes use of many existing solutions as parts of its integrated comprehensive platform. These solutions include:

- Alfresco: An Enterprise Content Management (ECM) system

- Activiti: A business process modelling and execution framework

- SOMO by ESTECO: An optimization and simulation integration platform

- Pentaho: A business intelligence platform.

Additional software components have been developed in order to facilitate the integration of these existing solutions. The solution is cloud based and collaborative space user needs just a browser.



Fig. 2. EPES Methodology main steps

The main steps in the EPES methodology (see Fig. 2.)

1. Collaborative work environment definition, strategic level

2. Collaborative project planning, operative level

3. Business Process Management cycle, operative level

The main concept of organization of work in the EPES platform is the "collaborative space". This is a concept that is quite similar to the concept of workspaces on platforms like Microsoft SharePoint, including both data and business process (or workflow) models, but provides additional functionality in the sense of configured computational services e.g. simulation and optimisation, that can operate directly on structured data files on the underlying content management platform.

Each collaborative space can also contain a customized semantic database of contextual data, which is used for organizing and linking together a possibly complex set of data, users, services and business processes. This context data provides a structured 
view of the contents of the collaborative space simultaneously from multiple points of view.

Each collaborative space is typically built to manage activities related to a product or a family of products or services. It involves data that is shared between different organizational units, such as marketing, business analytics, design, engineering and use and service e.g. maintenance activities. The goal is to avoid any need to keep data on personal or group-accessible repositories.

A methodology has been developed for managing the collaborative space. It is advisable to establish the collaborative space right at the planning stages of a project, and to maintain it to the end. In the case of product development, the collaborative space can live and adapt to the needs of the organization throughout the stages of the product life-cycle.

All content in a collaborative space is version-controlled. A collaborative space, or parts thereof, can be easily branched by creating a copy. This eases the parallel development of product alternatives, of which the best one can be selected at a later stage.

Some collaborative spaces are not used for projects, but for continuous activities, in which case the methodology proposes a business process management cycle of continuous improvement.

This work environment can be extended beyond the group of people who directly participate in the development processes. This enables, for example, a more direct form of feedback from the users to the engineers. It also connects varies engineering disciplines, group of engineers and managers.

Each of the actors in the defined Collaborative Spaces system has a role. The role could be, for example, an owner of the product, a user of the product, a service provider, a manufacturing or product-related engineer, a sales representative or a business decision-maker. Using the collaborative parts of the EPES system, any group of actors in the product service system community can distribute knowledge, collaborate, pin-point eco-constraints, bottlenecks and solve problems.

\section{EPES Use Cases}

The presented EPES approach is being applied in three industrial business cases (BC), to validate the proposed decision making solution within different application domains, as listed here.

BC1: Engineering maintenance services for optimizing maintenance and increasing availability of wind turbines. The decision processes involved here deal with the best scheduling of maintenance tasks to be taken for optimal maintenance of multiple wind turbines. The decision making and optimisation constrains include, service and operation history, weather conditions and forecast, availability of service resources and so on.

BC2: Power grid control systems for improved identification of improved monitoring of grid load and safety limits. Smart cable has features for temperature detection and monitoring at any point of the cable. Decision support methods are supporting the user in detecting trends in the grid load, ensuring thus that good load balancing deci- 
sions will be taken. Also new cable design is supported, e.g. material saving has multiple impacts on manufacturing, logistics and installation of cable network.

BC3: Support for optimized design and manufacturing of aircraft wings. Here, the decision support system addresses the optimal layout of manufacturing facilities in the conceptual design phase. User can fix some of the parameters of the facility, i.e. work shifts, cycle times and capacity, and the optimization returns the numbers of required facility elements; resources, personnel etc. The production data is aggregated with sustainability data to enable optimization in environmental point of view.

\section{Summary}

Sustainability-related issues are important and they are adding heavily to the complexity of the design process. The amount of data that is needed for decision-making is growing and multiple parameters and constraints must be considered simultaneously. Because multiple engineering disciplines, multiple actors and multiple life cycle stages are involved in the goal of sustainability, multidisciplinary optimisation (MDO) and multi-objective optimisation (MOO) techniques can seldom be avoided. When these techniques and tools are provided as services, the transparency and traceability of the decision making processes can be improved.

The EPES platform is a tool for managing both technically and organizationally complex tasks in a distributed organizational environment, such as virtual factory. The platform combines existing enterprise IT tools into a platform that is flexible and configurable and supports the simultaneous management of knowledge from multiple viewpoints.

Provision of engineering analyses and optimisation as services is one of the advantage of the EPES platform. When combined with knowledge management, communication and collaboration, business intelligence, and business process modelling and execution, a comprehensive platform is created. Instead of several desktop applications, engineering islands of analysis, the EPES system provides both integration and automation of the assessment methods that are necessary for tackling sustainability aspect.

Instead of directly addressing sustainability, the focus of the platform is on streamlining the processes and integrating the existing tools that are necessary for addressing it. In practice, by reducing the amount of required effort, the application of the solution also results in more sustainable outcomes, by allowing the enterprise to more efficiently use the available engineering resources, both human and computational.

The EPES approach is assessed in three companies from different sectors (wind farm maintenance, cable production and aeronautics), which represent typical examples of companies in need for such highly reconfigurable services to continuously optimize product performance and service delivery.

The maintenance and other services of industrial products, investment goods or design of complex, multi-disciplinary engineering products and collaborative product process service development are promising application areas for the EPES system. 
EPES system is an enterprise application, thus it needs customization and integration to existing legacy and other engineering systems. First time service set-up, and integration requires high expertise. Exploitation plans of the development is ongoing

Acknowledgements. The research presented in the paper has been carried out within the frames of the EPES, "Eco-Process Engineering System for Composition of Services to Optimize Product Life-Cycle" collaboration project, (www.epesproject.eu) co-funded by the European Commission under FoF-ICT-2011.7.3-285093 contract. The authors wish to express the acknowledgement to EC for the support and to all project partners for their contributions during the development presented in this paper. This document does not represent the opinion of the European Community, and the European Community is not responsible for any use that might be made of its content.

\section{References:}

1. Baños R., Manzano-Agugliaro F., Montoya F.G., Gil C., Alcayde A., Gómez J., Optimization methods applied to renewable and sustainable energy: A review, Renewable and Sustainable Energy Reviews, Volume 15, Issue 4, May 2011, Pages 1753-1766.

2. Seung J. K., Kara S., Kayis B., Economic and environmental assessment of product life cycle design: volume and technology perspective, Journal of Cleaner Production, Volume 75, 15 July 2014, Pages 75-85, ISSN 0959-6526.

3. Kleindorfer P. R., Singhal K., Van Wassenhove L. N., Sustainable Operations Management, Production and Operations Management, Volume 14, Issue 4, December 2005, pages 482-492.

4. Thiede S., Seow Y., Andersson J., Johansson B. (2013) Environmental aspects in manufacturing system modelling and simulation-State of the art and research perspectives. CIRP Journal of Manufacturing Science and Technology 6 (2013) 78-87.

5. Heilala J., Paju M., Montonen J., Ruusu R., Sorli M., Armijo A., Bermell-Garcia P., Astwood S., Quintana S.. (2012). Discrete Part Manufacturing Energy Efficiency Improvements with Modelling and Simulation. Conference Proceeding of APMS 2012. International Conference on Advances in Production Management Systems (APMS). Rhodes, Greece, 24-26 September 2012.

6. Design for Environment, Airbus Corporate Answer to Disseminate integrated Environmental Management sYstem (ACADEMY), ISSUE N 1 ACADEMY.

7. Sorli M., Armijo A. (2013). EPES: Engineering System for Optimization of Product Lifecycle through Adapted Eco-services. Procedia Engineering. Volume 63, 2013, Pages 310317. The Manufacturing Engineering Society International Conference, MESIC 2013.

8. Scholze S., Grama C., Kotte O. (2014). Eco Process Engineering System for highly customized industrial products, processes and services. SDM'2014 International Conference on Sustainable Design and Manufacturing. 28-30 April 2014 Cardiff, Wales, UK..

9. Heilala J., Ruusu R., Montonen J., Vatanen S., Bermell-Garcia P., Astwood S., Iwhiwhu C., Kavka C., Asnicar F., Ricco L. (2014). Product Concept Manufacturability and Sustainability Assessment with Eco Process Engineering System. SDM'2014 International Conference on Sustainable Design and Manufacturing. 28-30 April 2014 Cardiff, Wales, UK

10. Scholze S., Kotte O., Stokic D., Grama C. (2013) Context-sensitive decision support for improved sustainability of product lifecycle, KES IDT 2013, 5th International Conference on Intelligent Decision Technologies, Sesimbra Portugal, 2013. 